\title{
A Voltage-Mode Controlled High-Input-Power-Factor AC Line Conditioner with Minimized Output Voltage Harmonics
}

\author{
Yu-Kang Lo \\ Chern-Lin Chen
}

Dept. of Electrical Eng.

National Taiwan University

Taipei, Taiwan, R.O.C.

\begin{abstract}
A new AC line conditioner is presented. This system consists of a high-input-power-factor half-bridge switch-mode rectifier, DC-link capacitors and a lowoutput-harmonic half-bridge inverter. The rectifier is operated under voltage-mode feedback. No current sensing is required. The inverter is controlled by an EPROM-based modulator. Optimized SPWM patterns compensating DClink voltage ripple and dead time effects are programmed. Synchronizing the SMR and the inverter can eliminate the voltage imbalance between DC-link capacitors. The presented system is feasible for single- and three-phase applications.
\end{abstract}

\section{INTRODUCTION}

More and more modern industrial applications require stable single- or three-phase $\mathrm{AC}$ power sources while the utility systems are contaminated by increasingly proliferated power electronics equipment. The demands for $\mathrm{AC}$ line conditioners providing high-quality $\mathrm{AC}$ output power are rapidly growing. The line conditioners usually consist of AC/DC diode-bridge rectifiers, DC-link capacitors and DC/AC PWM inverters. Diode rectifiers usually produce serious line current distortion. Bulky filter capacitors are utilized to remove the low-order line-frequency voltage harmonics on inverter's output. System dynamic response is inevitably slow. Switch-mode rectifiers (SMR) have been proposed recently[1-3]. Their advantages include unity power factor, lower current harmonics, smaller size of capacitors and regulated DC-link voltage. For SMR control, current-mode feedback is more popular than conventional voltage-mode. However, the current-mode technique has the following disadvantages[4] :

1) Current sensing adds complexity and cost to circuit implementation.

2) Slope compensation is necessary for peak inductor current control and leads to decreased current control loop gain.

3) Varying switching frequency in hysteresis control causes serious EMI problems and dead zones in the zero crossings of the current waveforms.

In this paper, a new AC line conditioner is presented as shown in Fig. 1. The three-phase line conditioner for high-power applications is built by simply paralleling single-phase systems. This line conditioner consists of a high-input-power-factor half-bridge switch-mode rectifier, DC-link capacitors and a low-output-harmonic half-bridge inverter. The rectifier is operated under voltage-mode feedback[5]. There are only voltage control loops for input power factor correction and DC-link voltage regulation. No current sensing is required. The inverter is controlled by an fully-digitized EPROM-based PWM modulator. Optimized SPWM patterns compensating DC-link voltage ripple and dead time effects[6,7] are programmed. This approach featuring low cost, simple implementation and control is especially suitable in fixed-frequency applications. Synchronizing the SMR and the inverter can eliminate the voltage imbalance between DC-link capacitors

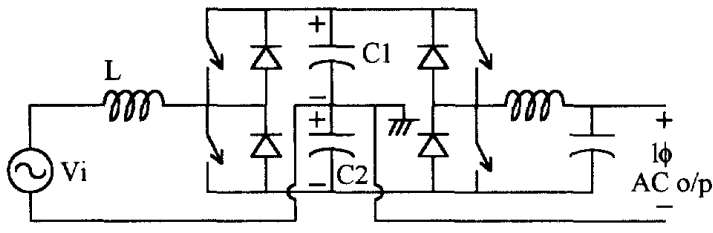

(a)

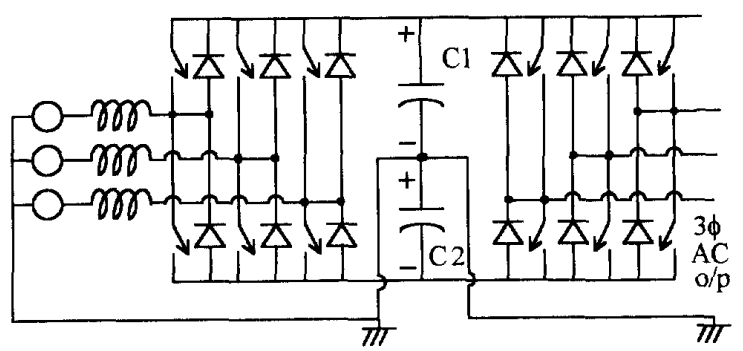

(b)

Fig. 1 Half-bridge AC line conditioner (a) $1 \phi$ (b) $3 \phi$

VOLTAGE-MODE CONTROL OF HALF-BRIDGE SMR

A general circuit for $1 \phi \mathrm{SMR}$ is proposed in [3], as shown in Fig. 2. $v_{u}$ is the pulse voltage which could be $E$ or $-E$ depending on the switching states. $E$ is the dc voltage of the output capacitor and $v_{u, 1}$ is the fundamental component of $v_{u}$. 

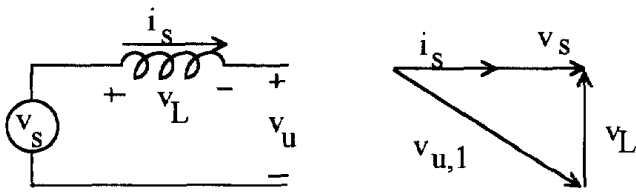

Fig. 2 General circuit and phasor diagram for $1 \phi$ SMR

From the phasor diagram, the principles of the voltagaemode control are deduced as follows

Let $v_{s}(t)=\sqrt{2} V_{s} \sin \omega t, i_{s}(t)=\sqrt{2} I_{s} \sin \omega t$ under steady state, $v_{L}(t)=L \cdot d_{s}(t) / d t=\sqrt{2} \omega L_{s} \cos \omega t$, then $v_{u, l}(t)=\sqrt{2}$

$\left(V_{s} \cdot \sin \omega t-\omega L I_{s} \cdot \cos \omega t\right)$. From the transfer characteristics of the SPWM inverter and the theorem of superposition, to produce an ac voltage $\mathrm{v}_{\mathrm{u}, 1}$, the reference signal or the control voltage has to be :

$$
\begin{aligned}
\mathrm{v}_{\text {control }} & =\mathrm{v}_{\mathrm{u}, 1} / \mathrm{E}=\frac{\sqrt{2} \mathrm{~V}_{\mathrm{s}}}{\mathrm{E}} \cdot \sin \omega \mathrm{t}-\frac{\sqrt{2} \omega \mathrm{LI}_{\mathrm{s}}}{\mathrm{E}} \cdot \cos \omega \mathrm{t} \\
& =\mathrm{k}_{1} \cdot \sin \omega \mathrm{t}-\mathrm{k}_{2} \cdot \cos \omega \mathrm{t}
\end{aligned}
$$

That is, the control voltage can be generated by summing an in-phase component and an in-quadrant component. $k_{1}$ is the parameter concerning the feedforward input voltage $v_{s}$ and $k_{2}$ concerning the feedback output voltage $E$.

The discussions above are based on the ideal sinusoidal source voltage. If the circumstances are under a distorted source voltage, the deduction is the same except for replacement of the pure sine-term. That is, $v_{\text {control }}=k_{1}{ }^{\prime} v_{s}(t)$ $k_{2} \cos \omega t$. Since the information about the source voltage is revealed in the first term of $v_{\text {control }}$, a sinusoidal input current can be obtained even with the distorted source present. The block diagram depicting the voltage-mode control for SMR is shown in Fig. 3.

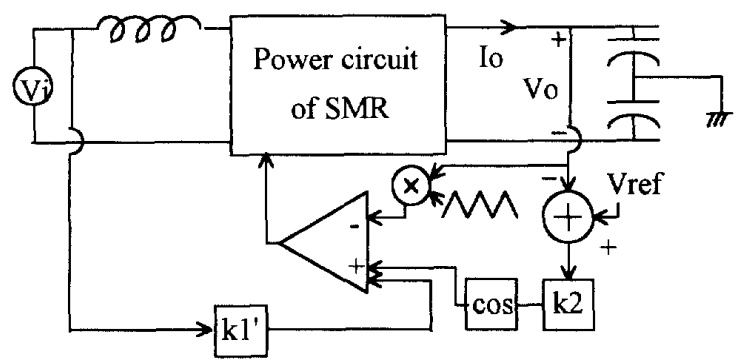

Fig. 3 Block diagram of voltage-mode control

\section{SELECTIONS OF L AND C}

The input inductor can be designed by analyzing Fig. 4(a) Because of the sinusoidal variation of the input current, its switching ripple varies period by period. The current ripple can be defined as the average current variations in a switching period : $\Delta \mathrm{I}=\left[(\mathrm{dI} / \mathrm{dt})_{\mathrm{inc}} \cdot \mathrm{T}_{\mathrm{sON}}+(\mathrm{dI} / \mathrm{dt})_{\mathrm{dec}} \cdot \mathrm{T}_{\mathrm{sOFF}}\right] / 2$. $(\mathrm{d} / / \mathrm{dt})_{\text {inc }}$ and $(\mathrm{dL} / \mathrm{dt})_{\mathrm{dec}}$ are the increasing and decreasing rates of input current. $T_{\mathrm{SON}}$ and $T_{\mathrm{SOFF}}$ are the on-time and off-time of the switch, respectively. By specifying the maximum current ripple $r_{i} \%$ and differentiating $\Delta I$ to $\theta$, we can solve for $\omega \mathrm{L}$ (see appendix 1 ):

$$
\omega \mathrm{L}=\frac{\mathrm{A} \cdot \mathrm{B}+\sqrt{(\mathrm{AB})^{2}-\left[\mathrm{A}^{2}-\left(2 \mathrm{P} / \mathrm{V}_{\mathrm{s}}\right)^{2}\right]\left(\mathrm{B}^{2}-\mathrm{V}_{s}^{2}\right)}}{\mathrm{A}^{2}-\left(2 \mathrm{P} / \mathrm{V}_{\mathrm{s}}\right)^{2}}
$$

$P$ is output power, $A=\left(P \cdot r_{i} \cdot m_{f} \cdot E\right) /\left(25 \cdot \pi \cdot V_{s}^{2}\right)$,

$$
\mathrm{B}=\mathrm{V}_{\mathrm{s}}+2 \cdot \mathrm{E}^{2} / \mathrm{V}_{\mathrm{s}}, \mathrm{mf}=\frac{\text { switching frequency }}{\text { fundamental frequency }} \text {. }
$$

The design of output capacitor is according to the output switching current, as shown in Fig. 4(b). Assuming that a dc current is fed to the load, then $I_{o}^{\prime}$ contains only harmonics of $I_{0}$. It is known that the 2nd-order line-frequency harmonic, $I_{o, 2}$, is the dominant one. The capacitance can then be determined as : $\Delta V_{0}=I_{0,2} / \omega C=V_{0} \cdot r_{v} \%$,

$$
\omega \mathrm{C}=100 \cdot \mathrm{I}_{0,2} /\left(\mathrm{V}_{0} \cdot \mathrm{r}_{\mathrm{v}}\right) \text {. }
$$

$\mathrm{V}_{\mathrm{o}}$ is the output voltage, which is $2 \cdot \mathrm{E}$ in the half-bridge topology.

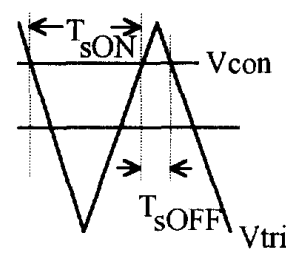

(a)

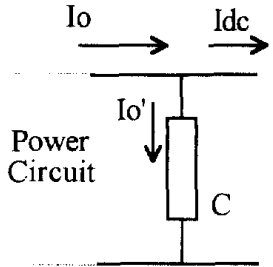

(b)
Fig. 4 Selections of (a) input inductor and (b) output capacitor

\section{COMPENSATION TECHNIQUES FOR INYERTERS}

With low-order line-frequency ripples on the DC-link voltage, typically-utilized sinusoidal PWM (SPWM) techniques will produce unwanted low-frequency harmonics in the inverter's output. Assuming that the DC-link voltage, $\mathrm{V}_{\mathrm{dc}}$, is ripple-free. Then the output of the inverter is an $\mathrm{AC}$ voltage modulated by a modulation function with frequency spectrum as depicted in Fig. 5. Harmonics are centered around the multiples of the switching frequency. This $\mathrm{AC}$ output can be written as :

$$
\mathrm{V}_{\mathrm{ac}}=\mathrm{V}_{\mathrm{dc}} \cdot\left[\mathrm{m}_{\mathrm{a}} \cdot \sin \omega \mathrm{t}+\right.
$$

where $m_{\mathrm{a}}$ is the amplitude modulation index and $\mathrm{m}_{\mathrm{f}}$ is the frequency modulation index. $l\left(\mathrm{~m}_{\mathrm{f}} \cdot \mathrm{n} \pm \mathrm{k}\right)$ is the amplitude of the corresponding $\left(m_{f} \cdot n+k\right)$ th-order harmonic. By filtering out the high-order harmonics, a fundamental $A C$ voltage, $V_{d c}$ $\cdot m_{a} \cdot \sin \omega t$, can be obtained.

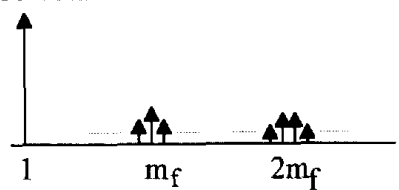

Fig. 5 Spectrum of a SPWM modulation function 
Let's now consider the case in which low-order harmonic $\mathrm{k} \cdot \mathrm{h}(\omega \mathrm{t})$ is superposed on the DC-link voltage, $\mathrm{V}_{\mathrm{dc}}{ }^{\prime}=\mathrm{V}_{\mathrm{dc}}{ }^{\circ}$ $(1+\mathrm{k} \cdot \mathrm{h}(\omega \mathrm{t}))$. The modulated $\mathrm{AC}$ output voltage then becomes :

$$
\begin{aligned}
\mathrm{V}_{\mathrm{ac}}^{\prime}= & \mathrm{V}_{\mathrm{dc}}(1+\mathrm{k} \cdot \mathrm{h}(\omega \mathrm{t})) \cdot\left[\mathrm{m}_{\mathrm{a}} \cdot \sin \omega \mathrm{t}+\right. \\
& \left.\sum_{\mathrm{n}+\mathrm{k}=\mathrm{odd}} l\left(\mathrm{~m}_{\mathrm{f}} \cdot \mathrm{n}+\mathrm{k}\right) \cdot \sin \left(\left(\mathrm{m}_{\mathrm{f}} \cdot \mathrm{n} \pm \mathrm{k}\right) \omega \mathrm{t}\right)\right] \\
= & \mathrm{V}_{\mathrm{ac}}+\mathrm{V}_{\mathrm{dc}} \cdot \mathrm{k} \cdot \mathrm{h}(\omega \mathrm{t}) \cdot \mathrm{m}_{\mathrm{a}} \sin \omega \mathrm{t}+\ldots . .
\end{aligned}
$$

Low-order output harmonics are produced due to the multiplication of two low-order terms, $k \cdot h(\omega t)$ and $m_{s} \cdot \sin \omega t$. By modifying the original reference function to $\frac{m_{a} \cdot \sin \omega t}{1+k \cdot h(\omega t)}$, the effects of low-order ripples can be removed.

For a bridge-type inverter, a short period of time is always included in control signals between turning one switch in an inverter leg off and turning the other one on. This is referred to the "dead time" which prevents two switches of an inverter leg from simultaneous conduction. It has been found that the dead time causes a reduction in the fundamental component of the output voltage and introduces low order harmonics which should not be present. A loadcurrent-dependent compensation method[7] can eliminate the output voltage harmonic distortion due to dead time effects. The principles of the compensation techniques are summarized here. When the load current is positive, the timing of the triggering signals to the upper switch in an inverter leg coincides with the ideal control patterns. This can be achieved by turning off the lower switch in advance and turning it on after a delay time. Conversely when the load current is negative the firing signals to the lower switch coincide with the ideal requirements. In this way the output $A C$ voltage waveform is almost the same with the original SPWM control patterns. An example of switching waveforms for dead time compensation is shown in Fig. 6.

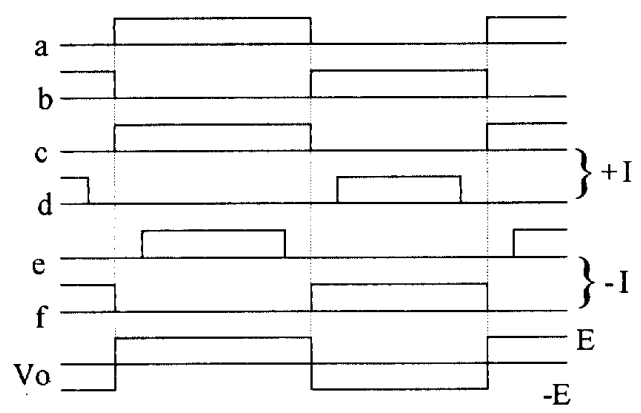

Fig. 6 Switching waveforms for dead time compensation $a=$ ideal triggering signal for upper switch $\mathrm{b}=$ ideal triggering signal for lower switch $c=$ control signal for upper switch when current $>0$ $\mathrm{d}=$ control signal for loser switch when current $>0$ $\mathrm{e}=$ control signal for upper switch when current $<0$ $\mathrm{f}=$ control signal for lower switch when current $>0$ $V_{0}=$ resulted $\mathrm{AC}$ output voltages
The above method is impossible to implement on the exiting system because it requires primary generation of control patterns for switches in advance. Here a scheme adopting reference sinewaves with offsets is proposed. As shown in Fig. 7, while comparison between $V_{t r i}$ and $V_{r o}$ produces the original SPWM signals, comparing $\mathrm{V}_{\mathrm{tr}}$ with $\mathrm{V}_{\mathrm{rt}}$ and $V_{r-}$ can give control signals with dead time compensation. The added dc-offsets can be related to the minimum required dead time, $\mathrm{d}_{\text {min }}$, as :

$|\Delta \mathrm{V}|=\hat{V}_{\mathrm{tri}} \cdot \mathrm{d}_{\text {min }}\left(4 \mathrm{f}_{\mathrm{s}}+\omega_{0} \mathrm{~m}_{\mathrm{a}}\right)$, where $\mathrm{f}_{\mathrm{s}}$ is the switching frequency and $\mathrm{m}_{\mathrm{g}}$ is the amplitude modulation index (see appendix 2).

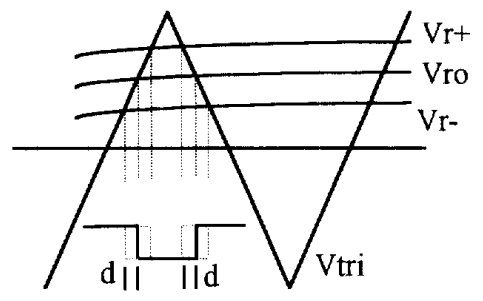

Fig. 7 SPWM with offsetted reference signals

\section{EPROM-BASED SPWM MODULATOR}

Conventionally, control signals fed to the PWM inverters are produced by electronic hardware or microprocessor. The cost and complexity of hardware implementation are considerable. On-line computation in the microprocessor approach is laborious and time-comsuming. These two approaches seem impractical when applied to the proposed compensation techniques. An EPROM-based SPWM modulator[8] can solve the problems mentioned above. The SPWM control patterns are pre-calculated by computing the intersections of a reference wave and a triangular carrier wave with numerical method. To program the analogue SPWM patterns into the EPROM, each pulse is composed of several consecutive digital '1's to represent its width. The duration between pulses are represented by consecutive ' 0 's. This digitized SPWM pattern can then be retrieved sequentially by incrementing the address counter with a clock. This modulator features the advantages of low cost, fast response, simple control and implementation.

In the proposed EPROM-based modulator for fixedfrequency inverters, an optimized SPWM switching function compensating DC-link voltage ripple and dead time effects can be off-line calculated and pre-programmed. A fixedfrequency oscillator with counters retrieves the PWM patterns by counting through the addresses of the EPROM. A reset signal is sent at the end of a programmed period from the EPROM to ensure a complete cycle. The block diagram of the proposed modulator is illustrated in Fig. 8. The fixed-frequency oscillator can be replaced by a tracking PLL circuit when the line frequency varies 


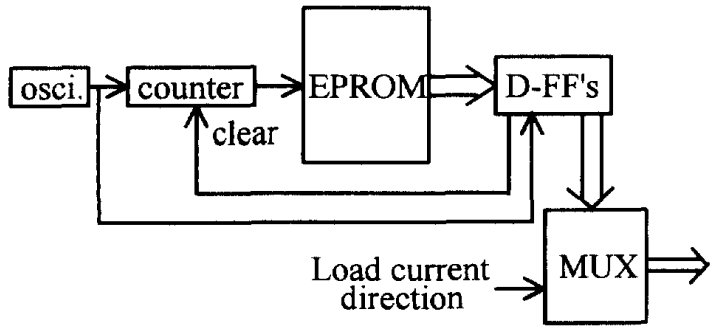

Fig. 8 Block diagram of the proposed high-performance EPROM-based SPWM modulator

\section{RESULTS AND DISCUSSIONS}

Simulations have been performed on the $1 \phi$ AC line conditioner with the following operating conditions :

Source voltage $\mathrm{V}_{\mathrm{s}}=110 \mathrm{~V}(\mathrm{rms}), 60 \mathrm{~Hz}$.

AC-side impedance $\omega \mathrm{L}=5 \Omega$

DC-link capacitance $\omega \mathrm{C}=0.81 / \Omega$

Output power $\mathrm{P}=1 \mathrm{~kW}$

Regulated DC-link voltage $=400 \mathrm{~V}$

Switching frequency $=2 \mathrm{kHz}$

Amplitude modulation index $\mathrm{m}_{\mathrm{a}}=0.78$

Fig. 9(a) shows the input current of $1 \phi$ SMR. Fig. $9(\mathrm{~b})$ is the output voltage and Fig. $9(\mathrm{c})$ is the spectrum of input current (THD=8.32\%). The switching frequency is set to $2 \mathrm{kHz}$ for visual clarity. If a realizably higher switching frequency, say, $20 \mathrm{kHz}$, is adopted, the THD is $1.65 \%$ which is well within the maximum allowable limit of $8 \%$ in IEEE-519.

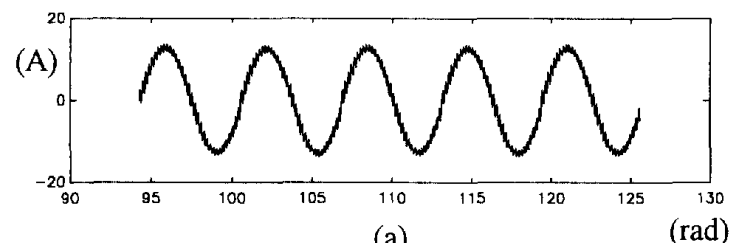

(a)

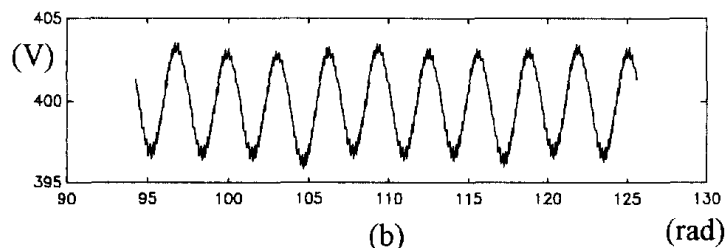

(b)

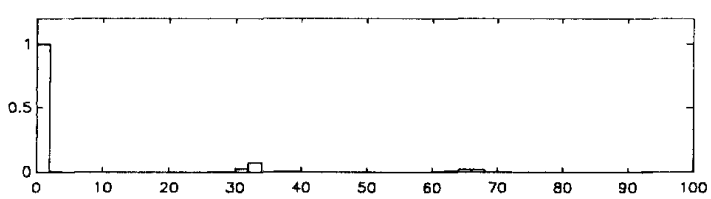

(c)

Fig. 9(a) Input current (b) Output voltage (c) Spectrum of (a)
Fig. 10 illustrates the ripple compensation of a modified modulation function, where $120 \mathrm{~Hz}$ ripple amplitude is $20 \%$. Fig. 10(a) is the normalized inverter's output voltage and (b) is the spectrum without compensation. Fig. 10(c) and (d) show those with compensation. The differences between Fig. 10(a) and Fig. 10(c) are not obvious since the compensation is revealed in the high-freqyency modulation function. However, in Fig. 10(d) the 3rd harmonic is reduced greatly compared to that in Fig. 10(b). By filtering out the harmonics which are multiples of the switching frequency, qualified $\mathrm{AC}$ outputs can be supplied to the loads.

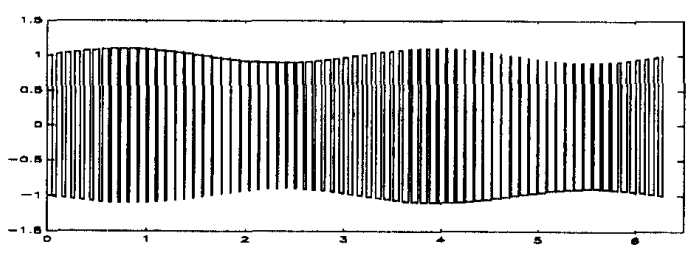

(a) (rad)

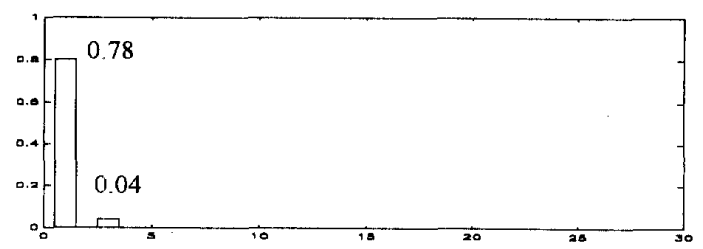

(b)

f/fo

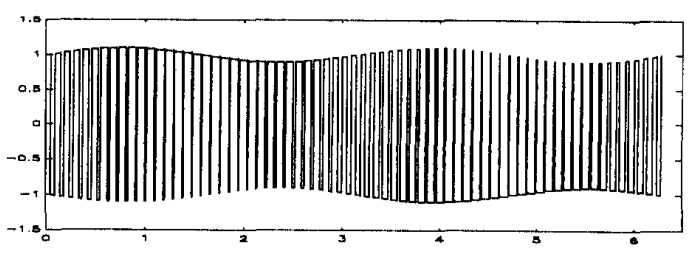

(c)

(rad)

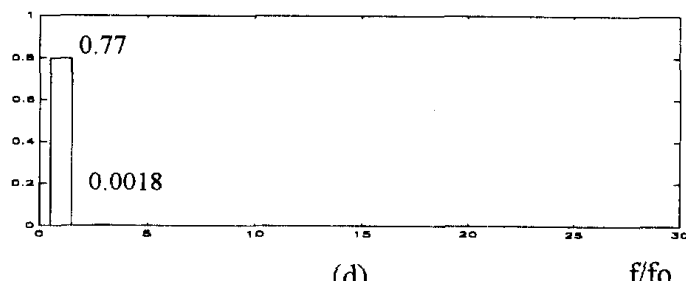

(d)

f/fo

Fig. 10(a) Normalized output voltage without compensation (b) Spectrum of (a)

(c) Normalized output voltage with compensation

(d) Spectrum of (c)

Fig. 11 shows the input currents of a $3 \phi$ SMR. 




Fig. 11 Input currents of $3 \phi$ SMR

In the laboratory experiments, a $1 \phi$ half-bridge SMR is built and the results are recorded. Mlustrated in Fig. 12 is the input current and input voltage under voltage-mode control. The source voltage $(50 \mathrm{Vms}, 60 \mathrm{~Hz})$ is supplied by an $\mathrm{AC}$ power supply. Input inductance and output capacitance are $2.6 \mathrm{mH}$ and $1150 \mu \mathrm{F}$, respectively. Switching frequency is $50 \mathrm{kHz}$ and a $667 \Omega$ resistive load is used. Output DC voltage is $200 \mathrm{~V}$.



Fig. 12 Input voltage and input current (20V/div., $1 \mathrm{~A} / \mathrm{div}$.

Shown in Fig. 13(a) is the SPWM control signals fed to switches when the load current is positive. The upper part is the same as the original pattern. The lower part advances turning-offs and delays turning-ons to implement dead-time compensation. Fig. 13(b) depicts the SPWM control signals when load current is negative. The upper part advances turning-offs and delays turning-ons and the lower part is the original pattern.

In the half-bridge SMR, $\mathrm{Cl}$ charges and $\mathrm{C} 2$ discharges in the positive half-period, and vice versa. This causes the voltage imbalance between $\mathrm{C} 1$ and $\mathrm{C} 2$. In the proposed $\mathrm{AC}$ line conditioner, SMR charges/discharges and inverter discharges/charges the same capacitor. In this way, the voltage imbalance problem can be solved by synchronizing the SMR and inverter stages.



(a)

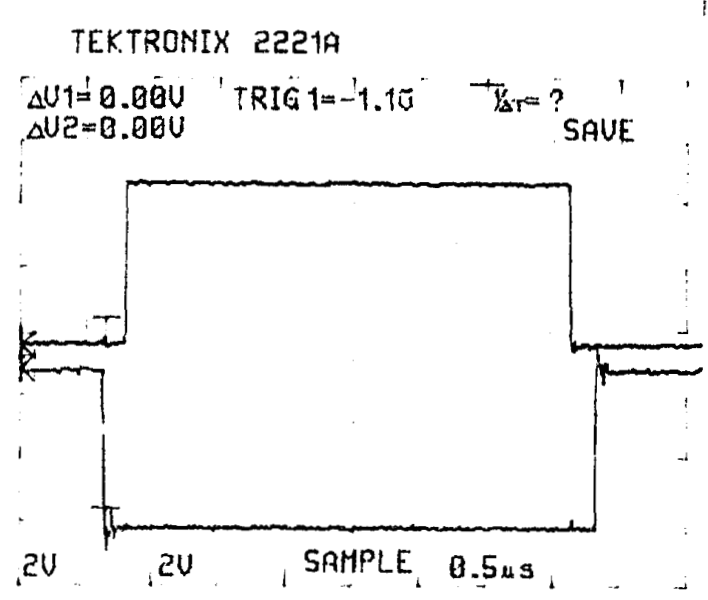

(b)

Fig. 13 SPWM control signals for inverter switches when (a) load current $>0$ (b) load current $<0$

\section{CONCLUSION}

A novel control scheme for a new AC line conditioner is presented. In this scheme, a half-bridge SMR with voltage-mode control serves as the $\mathrm{AC} / \mathrm{DC}$ converter. No inner current loop is required. Based on the principles of the well-developed SPWM, relative circuit simplicity, low cost and regulated DC-link voltage can be achieved. The $\mathrm{DC} / \mathrm{AC}$ inverter is also a half-bridge type. A fully-digitized SPWM modulator with compensation of DC-link voltage ripple and dead time effects is utilized. Synchronizing the SMR and the inverter can eliminate the voltage imbalance between DC-link capacitors. High power capability or 
multi-phase applications can be implemented by simply paralleling $1 \phi$ modules.

The applications of interfacing regulated DC or qualified $\mathrm{AC}$ sources with utility systems proliferate extensively. The proposed scheme provides a potentially effective and economic way to improve the performance of line conditioners.

\section{REFERENCES}

[1] P. N. Enjeti and R. Martinez, "A high performance single phase $A C$ to $D C$ rectifier with input power factor correction," IEEE, APEC '93, Conf. Proceedings, pp. 190-195.

[2] N. Mohan, "A novel approach to minimize line-current harmonics in interfacing power electronics equipment with 3-phase utility systems," IEEE Summer power meeting, paper 92 SM 498-6 PWRD, Seattle, WA, July 12-16, 1992

[3] J. C. Salmon, "Circuit topologies for single-phase voltage-doubler boost rectifier," IEEE PESC '92 Proceedings, pp. 549-556.

[4] L. D. Salazar and P. D. Ziogas, "A novel current-assisted output voltage control technique for switch-moderectifier converters," IEEE Trans. Power Electronics, Vol. 7, No. 3, pp. 444-452, July 1992.

[5] J. W. Dixon and B. T. Ooi, "Indirect current control of a unity power factor sinusoidal current boost type three-phase rectifier," IEEE Tran. Ind. Elec., Vol. 35, No. 4, pp. 508-515, Nov. 1988.

[6] P. N. Enjeti, W. Shireen, " A new technique to reject DC-link voltage ripple for inverters operating on programmed PWM waveforms," IEEE Trans. Power Electronics, Vol. 7, No. 1, pp. 171-180, Jan. 1992.

[7] R. C. Dodsin, P. D. Evans, H. T. Yazdi, and S. C. Harley, "Compensating for dead time degradation of PWM inverter waveforms," IEE Proc., Vol. 137, Pt. B, No. 2, pp. 73-81, Mar. 1990.

[8] Y. K. Lo, C. L. Chen, J. S. Lin and J. Y. Wu, "A new high-performance AC-to-AC conversion system," IEEE, IECON '93, Conf. Proceedings, pp. 824-829.

\section{APPENDIX 1}

From Fig. 4(a), the maximum current ripple under voltage-mode control can be calculated as follows :

$$
\begin{aligned}
& \mathrm{T}=\frac{2 \pi}{\omega_{\mathrm{s}}}=\frac{1}{\mathrm{f}_{1} \cdot \mathrm{m}_{\mathrm{f}}} ; \text { slope of } \mathrm{V}_{\mathrm{tri}}= \pm \frac{1}{\mathrm{~T} / 4}= \pm \frac{4}{\mathrm{~T}} ; \\
& \text { So } T_{\mathrm{sON}}=2 \cdot\left(\frac{V \operatorname{con}}{\text { slope }}+\frac{T}{4}\right)=2 \cdot\left(\frac{m_{a} \cdot \sin (\theta-\phi)}{\text { slope }}+\frac{T}{4}\right) \\
& =\frac{T}{2}\left(1+m_{a} \cdot \sin (\theta-\phi)\right) ; \\
& \mathrm{T}_{\mathrm{sOFF}}=\mathrm{T}-\mathrm{T}_{\mathrm{sGN}}=\frac{\mathrm{T}}{2}\left(1-\mathrm{m}_{\mathrm{a}} \cdot \sin (\theta-\phi)\right) ;
\end{aligned}
$$

where $V \operatorname{con}=V_{s} \sin \theta-$ WLI $_{\mathrm{s}} \cos \theta=\mathrm{m}_{\mathrm{a}} \cdot \sin (\theta-\phi)$,

$\mathrm{m}_{\mathrm{a}}=\sqrt{\mathrm{V}_{\mathrm{s}}^{2}+\left(\omega \mathrm{LI}_{\mathrm{s}}\right)^{2}} / \mathrm{E}$, and $\phi=\tan ^{-1} \frac{\omega \mathrm{LI}_{\mathrm{s}}}{\mathrm{V}_{\mathrm{s}}}$

According to the definition of current ripples :

$$
\begin{aligned}
\Delta \mathrm{I} & =\left[(\mathrm{dI} / \mathrm{dt})_{\text {inc. }} \cdot \mathrm{T}_{\mathrm{sON}}+(\mathrm{dI} / \mathrm{dt})_{\mathrm{dec}} \cdot \mathrm{T}_{\mathrm{sOFF}}\right] / 2 \\
& =\frac{1}{2}\left[\frac{\mathrm{V}_{\mathrm{s}} \sin \theta+\mathrm{E}}{\mathrm{L}} \cdot \frac{\mathrm{T}}{2}\left(1+\mathrm{m}_{\mathrm{a}} \cdot \sin (\theta-\phi)\right)+\right. \\
\left.\frac{\mathrm{E}-\mathrm{V}_{\mathrm{s}} \sin \theta}{\mathrm{L}} \cdot \frac{\mathrm{T}}{2}\left(1-\mathrm{m}_{\mathrm{a}} \cdot \sin (\theta-\phi)\right)\right] & \\
& =\frac{\mathrm{T}}{2 \mathrm{~L}}\left[\mathrm{~V}_{\mathrm{s}} \cdot \mathrm{m}_{\mathrm{a}} \cdot \sin \theta \sin (\theta-\phi)+\mathrm{E}\right] \\
& =\frac{\mathrm{T}}{4 \mathrm{~L}}\left[\mathrm{~V}_{\mathrm{s}} \cdot \mathrm{m}_{\mathrm{a}} \cdot(\cos \phi-\cos (2 \theta-\phi))+2 \mathrm{E}\right]
\end{aligned}
$$

By maximizing $\Delta \mathrm{I}$ with respect to $\theta$, a maximum current ripple can be obtained at $\theta=\frac{180^{\circ}+\phi}{2}$. The minimum $\omega \mathrm{L}$ thus can be calculated :

$$
\begin{aligned}
& \Delta \mathrm{I}_{\max }=\frac{\mathrm{T}}{4 \mathrm{~L}}\left[\mathrm{~V}_{\mathrm{s}} \cdot \mathrm{m}_{\mathrm{a}} \cdot(\cos \phi+1)+2 \mathrm{E}\right] \leq \mathrm{I}_{\mathrm{s}} \cdot \mathrm{r} \% \\
& \mathrm{~V}_{\mathrm{s}} \cdot \frac{\sqrt{\mathrm{V}_{\mathrm{s}}^{2}+(\omega \mathrm{LI})^{2}}}{\mathrm{E}} \cdot\left(\frac{\mathrm{V}_{\mathrm{s}}}{\sqrt{\mathrm{V}_{\mathrm{s}}^{2}+(\omega \mathrm{LI})^{2}}}+1\right)+2 \mathrm{E} \leq \frac{\mathrm{I}_{\mathrm{s}} \cdot \mathrm{r} \cdot \omega \mathrm{L} \cdot \mathrm{m}_{\mathrm{f}}}{50 \pi} \\
& \sqrt{(\omega \mathrm{LI})^{2}+\mathrm{V}_{\mathrm{s}}^{2}} \leq \frac{\mathrm{I}_{\mathrm{s}} \cdot \mathrm{r} \cdot \mathrm{m}_{\mathrm{f}} \cdot \mathrm{E}}{50 \pi \cdot \mathrm{V}_{\mathrm{s}}} \omega \mathrm{L}-\left(\mathrm{V}_{\mathrm{s}}+2 \cdot \mathrm{E}^{2} / \mathrm{V}_{\mathrm{s}}\right) \\
& \quad \leq \mathrm{A} \cdot \omega \mathrm{L}-\mathrm{B} \\
& \left(\mathrm{A}^{2}-\mathrm{I}_{\mathrm{s}}{ }^{2}\right)(\omega \mathrm{L})^{2}-2 \mathrm{BA} \cdot \omega \mathrm{L}+\mathrm{B}^{2}-\mathrm{V}_{\mathrm{s}}{ }^{2} \geq 0 \\
& \text { Let } \mathrm{I}_{\mathrm{s}}=2 \mathrm{P} / \mathrm{V}_{\mathrm{s}}, \text { then } \\
& \omega \mathrm{L}=\frac{\mathrm{A} \cdot \mathrm{B}+\sqrt{(\mathrm{AB})^{2}-\left[\mathrm{A}^{2}-\left(2 \mathrm{P} / \mathrm{V}_{\mathrm{s}}\right)^{2}\right]\left(\mathrm{B}^{2}-\mathrm{V}_{s}^{2}\right)}}{\mathrm{A}^{2}-\left(2 \mathrm{P} / \mathrm{V}_{\mathrm{s}}\right)^{2}}
\end{aligned}
$$

\section{APPENDIX 2}

According to Fig. 7, the minimum offset voltage required for dead time compensation can be deduced as :

The slope of triangular wave is $2 \mathrm{~V}_{\mathrm{tri}} /\left(\mathrm{T}_{\mathrm{s}} / 2\right)=4 \mathrm{f}_{\mathrm{s}} \cdot \mathrm{V}_{\mathrm{tri}}$.

At some $t_{0}$, the slope of $V_{r o}$ is $\omega_{0} \cdot m_{a} \cdot V_{t r} \cdot \cos \left(\omega t_{0}\right)$.

The intersection can then be calculated by solving the following two equations :

$$
\begin{aligned}
& y=4 f_{s} \cdot V_{t r i}\left(t-t_{0}\right) \\
& y-m_{a} \cdot V_{t r i} \cdot \sin \left(\omega t_{0}\right)=\omega_{0} \cdot m_{a} \cdot V_{t r i} \cdot \cos \left(\omega t_{0}\right)\left(t-t_{0}\right) \\
& \Rightarrow \Delta t=t-t_{0}=\frac{m_{a} \cdot \sin \omega_{0} t_{0}}{4 f_{s}-\omega_{0} \cdot m_{a} \cdot \cos \left(\omega_{0} t_{0}\right)} .
\end{aligned}
$$

If a dc offset $\Delta V$ is added in the reference wave, the resulted drift in $t$-axis is :

$$
\mathrm{d}=\frac{\Delta \mathrm{V} / \mathrm{V}_{\mathrm{tri}}}{4 \mathrm{f}_{\mathrm{s}}-\omega_{0} \cdot \mathrm{m}_{\mathrm{a}} \cdot \cos \left(\omega_{0} \mathrm{t}_{0}\right)} .
$$

For a specified minimum dead time $d_{\text {min }}$, the required $\Delta V$ is :

$$
\begin{aligned}
\Delta \mathrm{V} & =\mathrm{V}_{\mathrm{tri}} \cdot \mathrm{d}_{\min }\left(4 \mathrm{f}_{\mathrm{s}}-\omega_{0} \cdot \mathrm{m}_{\mathrm{a}} \cdot \cos \left(\omega \mathrm{t}_{0}\right)\right)_{\min } \\
& =\mathrm{V}_{\mathrm{tri}} \cdot \mathrm{d}_{\min }\left(4 \mathrm{f}_{\mathrm{s}}+\omega_{0} \cdot \mathrm{m}_{\mathrm{a}}\right)
\end{aligned}
$$

